\title{
AS ACCÕES DAS COOPERATIVAS AGRÍCOLAS FRENTE À CADEIA PRODUTIVA DO BIODIESEL NO RIO GRANDE DO SUL: EVIDÊNCIAS EM DIREÇÃO AO DESENVOLVIMENTO REGIONAL
}

\author{
Marluci Casalini Wildner ${ }^{1}$ \\ Sibele Vasconcelos de Oliveira ${ }^{2}$ \\ Orlando Martinelli Junior ${ }^{3}$
}

\begin{abstract}
RESUMO
As políticas públicas brasileiras direcionadas à segurança energética acompanham as iniciativas internacionais, com destaque para ações intersetoriais e transversais. Nas últimas décadas, o país vem se destacando na produção de biocombustíveis, dentre os quais, citam-se os derivados de cultivares agrícolas. Diante deste contexto, o presente estudo tem por objetivo analisar a inserção das cooperativas agropecuárias na cadeia produtiva do biodiesel no Rio Grande do Sul. Para tanto, foram realizadas pesquisas bibliográficas, bem como a análise de dados secundários sobre o tema. Constatou-se que a inserção das cooperativas na cadeia produtiva do biodiesel é incentivada pelo PNPB e suas respectivas estratégias de inserção da agricultura familiar ao mercado energético. As cooperativas atuam como intermediárias e facilitadores da produção, distribuição e comercialização agrícola. Neste sentido, afirma-se que as cooperativas são importantes agentes econômicos de fomento ao desenvolvimento regional, bem como elo fundamental para o crescimento da cadeia produtiva do biodiesel.
\end{abstract}

Palavras-chave: agricultura familiar, biocombustíveis, cooperativismo, desenvolvimento rural.

\section{THE ACTIONS OF AGRICULTURAL COOPERATIVES FACING THE BIODIESEL PRODUCTION CHAIN IN RIO GRANDE DO SUL: EVIDENCE FOR REGIONAL DEVELOPMENT}

\begin{abstract}
Brazilian public policies focused on energy security follow international initiatives, with emphasis on intersectoral and transversal actions. In the last decades, the country has

\footnotetext{
${ }^{1}$ Graduada em Ciências Econômicas (UNIJUI). Mestra em Economia e Desenvolvimento (UFSM). Docente do Curso de Graduação em Engenharia de Produção na Sociedade Educacional Três de Maio (SETREM). Email: wildnermarluci@gmail.com

${ }^{2}$ Graduada em Ciências Econômicas (UFSM). Especialista em Finanças (UNIFRA). Mestra em Extensão Rural (UFSM). Doutora em Agronegócios (UFRGS). Docente no Programa de Pós-Graduação em Economia e Desenvolvimento e no Programa de Pós-Graduação em Agronegócios da Universidade Federal de Santa Maria (UFSM). E-mail: sibele.oliveira@ufsm.br

${ }^{3}$ Graduado em Ciências Econômicas (UNICAMP). Mestre em Economia (USP). Doutor em Ciências Econômicas (UNICAMP). Docente no Programa de Pós-Graduação em Economia do Desenvolvimento da Universidade Federal de Santa Maria (UFSM). E-mail: orlando.martinelli@gmail.com
} 
been highlighting in the production of biofuels, among which we mention the derivatives of agricultural cultivars. In this context, the present study aims to analyze the insertion of agricultural cooperatives in the biodiesel production chain in Rio Grande do Sul. For this purpose, bibliographical research was done, as well as the analysis of secondary data on the subject. It was verified that the insertion of the cooperatives in the biodiesel production chain is encouraged by the PNPB and its respective strategies of insertion of the familiar agriculture to the energy market. Cooperatives act as intermediaries and facilitators of agricultural production, distribution and marketing. In this sense, it is affirmed that the cooperatives are important economic agents of foment to the regional development, as well as fundamental link for the growth of the productive chain of the biodiesel.

Key words: biofuels, cooperativism, family farming, rural development.

\section{INTRODUÇÃO}

As transformações políticas e socioeconômicas, aliadas aos avanços em tecnologia, condicionam uma nova conjuntura de produção. Em especial, a preocupação mundial com a segurança energética e com a preservação do meio ambiente, expressas em termos da maior demanda por produtos e serviços ambientalmente sustentáveis, motivam as discussões sobre as potencialidades da oferta e dos empregos das energias renováveis (GRAEF, 2012).

Neste sentido, nos anos 1990, muitos países iniciaram suas iniciativas no planejamento e ações em direção à produção e uso de biodiesel. Pautado na construção de políticas públicas com diretrizes apoiadoras do desenvolvimento sustentável e regional, e em atendimento às inquietações com os limites do acesso aos combustíveis não renováveis, o Brasil lançou o Programa Nacional de Produção e Uso do Biodiesel (PNPB) em 2005 (MDA, 2010).

O marco regulatório do biodiesel no Brasil está vinculado à promulgação da Lei no 11.097 de 13 de janeiro de 2005, que passou a incluir de maneira definitiva e oficial a produção de biodiesel na matriz energética do país (MDA, 2010). Em suma, o PNPB compreende a organização e estruturação da cadeia produtiva do biodiesel, considerando os aspectos de inclusão social, geração de renda, emprego e desenvolvimento regional.

Vale ressaltar que no Brasil o maior percentual de biodiesel é produzido a partir do óleo de soja, que é proveniente da soja in natura. A originação dos grãos é realizada nas propriedades agrícolas e, após seu tratamento e armazenamento, é disponibilizada para aquisição das processadoras de biodiesel. Destarte, no Rio Grande do Sul, a cadeia produtiva do biodiesel conta com a proeminência das cooperativas agrícolas nos espaços dos agronegócios, já que essas organizações possuem um aglomerado de produtores de matéria-prima.

Segundo dados da FECOAGRO (2017) as cooperativas gaúchas detêm aproximadamente $31 \%$ da safra $2014 / 2015$ de soja no estado, representando 4.880.066 toneladas de soja. Na safra de 2016/2017, o estado bateu recordes de produção, em consequência, houve o crescimento do volume de grãos recebidos por parte das cooperativas. Em síntese, nas safras 2015/2016 e 2016/2017, as cooperativas receberam, respectivamente, 5.638 .988 toneladas e 7.205.483 toneladas da soja produzida no estado.

Diante deste contexto, a Organização das Nações Unidas para Agricultura e Alimentação (FAO, 2016) argumenta que as ações das cooperativas agrícolas são um importante mecanismo de promoção ao desenvolvimento rural e regional. Estas são 
responsáveis por oferecer oportunidades de mercado aos agricultores familiares, oferecer capacitações para a gestão de recursos naturais, viabilizar o acesso à informação, tecnologia, inovação e serviços de extensão agrária (FAO, 2016). Sobretudo, argumenta-se que os relacionamentos comerciais e institucionais que estas organizações desempenham na cadeia produtiva do biodiesel são vetores de crescimento do setor.

Sendo assim, o presente estudo tem por objetivo compreender a inserção das cooperativas agrícolas na cadeia produtiva do biodiesel no estado do Rio Grande do Sul. Para tanto, empreendeu-se uma pesquisa bibliográfica, seguida da análise de dados secundários sobre a produção, distribuição e comercialização por parte das cooperativas agrícolas inseridas na cadeia produtiva do biodiesel.

A presente pesquisa está organizada, além desta introdução, em cinco seções. Na seção 02, é apresentada uma breve revisão sobre o Programa Nacional de Produção e Uso de Biodiesel, implantado há aproximadamente doze anos no Brasil. Na seção 03, apresentam-se algumas características da cadeia produtiva do biodiesel no Brasil e, em particular, no Rio Grande do Sul. Na seção 04, são apresentados elementos que corroboram a importância das cooperativas agrícolas gaúchas frente à cadeia produtiva do biodiesel no Rio Grande do Sul. Por fim, expõemse as considerações finais e as referências consultadas ao longo do período de estudo.

\section{POLÍTICAS PÚBLICAS E A PROMOÇÃO DA PRODUÇÃO DE ENERGIAS RENOVÁVEIS NO BRASIL}

O biodiesel é um biocombustível derivado de biomassa renovável, de fontes renováveis, que pode ser produzido de várias matérias-primas, como a gordura animal e os óleos vegetais. Entre os óleos vegetais originadores de insumos de produção para o biodiesel, citam-se: a mamona, o dendê, o girassol, a canola, o gergelim, a soja, dentre outros. Estas fontes de energia são consideradas renováveis, logo o biodiesel gerado é uma energia renovável (MDA, 2010).

Tecnicamente, o biodiesel gerado a base de óleos pode ser produzido a partir de duas principais formas: a transesterificação e a hidroesterificação. A primeira e mais recorrente na cadeia brasileira consiste na adição de metanol ou etanol ao óleo. Associado a um catalisador, o processo desencadeado institui a separação do glicerol do óleo vegetal, resultando no biodiesel. Nesse processo, a glicerina é removida do óleo vegetal, deixando mais fino e reduzindo a viscosidade, rendendo ainda coprodutos como a glicerina (KNOTHE et al., 2006).

Uma nova oportunidade para a produção de biodiesel é descrita por Maia (2012) como a hidroesterificação. O processo de produção envolve uma etapa de hidrólise e, posteriormente, uma etapa de esterificação. Nesta modalidade, é possível utilizar como matéria-prima qualquer produto graxo, por exemplo, gordura animal, óleo vegetal ou até óleo de fritura. Nesta modalidade, a acidez da matéria-prima ou a umidade do insumo não exerce diferencial na matéria-prima e como coprodutos produz uma glicerina de alta qualidade (MAIA, 2012).

A sequência para produção de biodiesel produzido a partir de grãos oleaginosos, conforme a transesterificação, que é um dos métodos mais populares nas usinas brasileiras, pode ser visualizada por meio da Figura 1. Em síntese, após o recebimento da matéria-prima, no caso os grãos oleaginosos, procede-se com o prensamento. Deste processo, resulta a torta, mais conhecida como o farelo e o óleo. Posteriormente, é adicionado o metanol ou etanol ao óleo. Então, dá-se processo de transesterificação, onde são produzidos os coprodutos e ao fim do processo se tem o biodiesel (QUESSADA et al., 2010; PEDRINI, 2012). 
Figura 1 - Esquema da produção de biodiesel pelo processo de transesterificação.

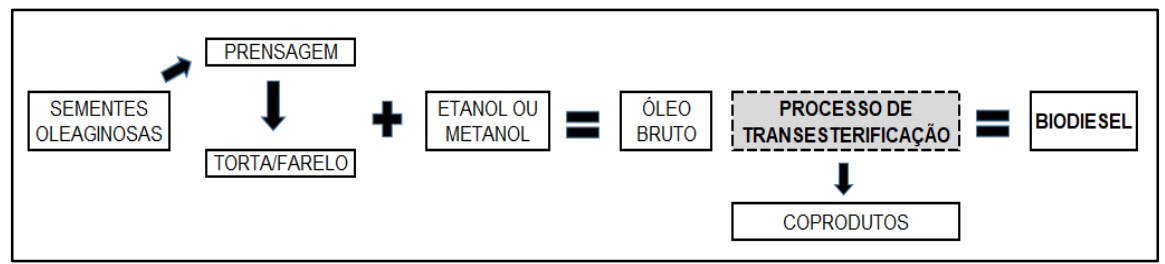

Fonte: Adaptado de Quessada et al. (2010) e Pedrini (2012).

Após a entrada do óleo de soja na planta industrial de processamento de biodiesel, são necessários alguns testes de qualidade. Obtendo-se resultados positivos, é adicionado ao óleo de soja o etanol ou metanol. Logo em seguida, ocorre a separação do glicerol do óleo e, como resultado, tem-se o biodiesel e os demais coprodutos desta reação, como a glicerina e o tocoferol (KNOTHE et al., 2006).

Vale destacar que o biodiesel pode ser substituído de forma total ou parcial ao óleo diesel de petróleo, em motores automotivos ou estacionários (BRASIL, 2005; MDA, 2010). Quando da instituição do Programa Nacional de Produção e Uso do Biodiesel no ano de 2005, previu-se a adição de percentual mínimo de biodiesel ao diesel de petróleo, sendo a regulação da produção atribuída à Agência Nacional do Petróleo, Gás Natural e Biocombustíveis vinculada ao Ministério de Minas e Energia (BRASIL, 2005).

Atualmente, o Governo Federal instituiu este percentual de adição em 8\%. Em março de 2016, a Presidência da República publicou a Lei 13.263, elevando a adição de biodiesel ao diesel comum no Brasil durante um período de 36 meses. Até março de 2019, em todo território nacional, deve ser adicionado $10 \%$ de biodiesel ao diesel comum (BRASIL, 2016).

Além da proposta de aumento gradual da mistura do biodiesel ao diesel, foi estabelecido um novo parâmetro à adição de biodiesel ao diesel, chamado de autorizativo, que consiste em autorizar a adição em quantidade superior ao percentual de adição obrigatória fixado em lei, podendo variar de $18 \%$ a $27,5 \%$ de biodiesel acrescentado ao diesel de petróleo (BRASIL, 2014). A Figura 2 ilustra a evolução da regulamentação do setor, em consonância com a proposta de adição de biodiesel ao diesel de petróleo, reafirmando a escolha política pelo crescimento desta cadeia e da utilização de fontes energéticas renováveis. 
Figura 2 - Evolução do marco legal da produção e uso do biodiesel no Brasil.

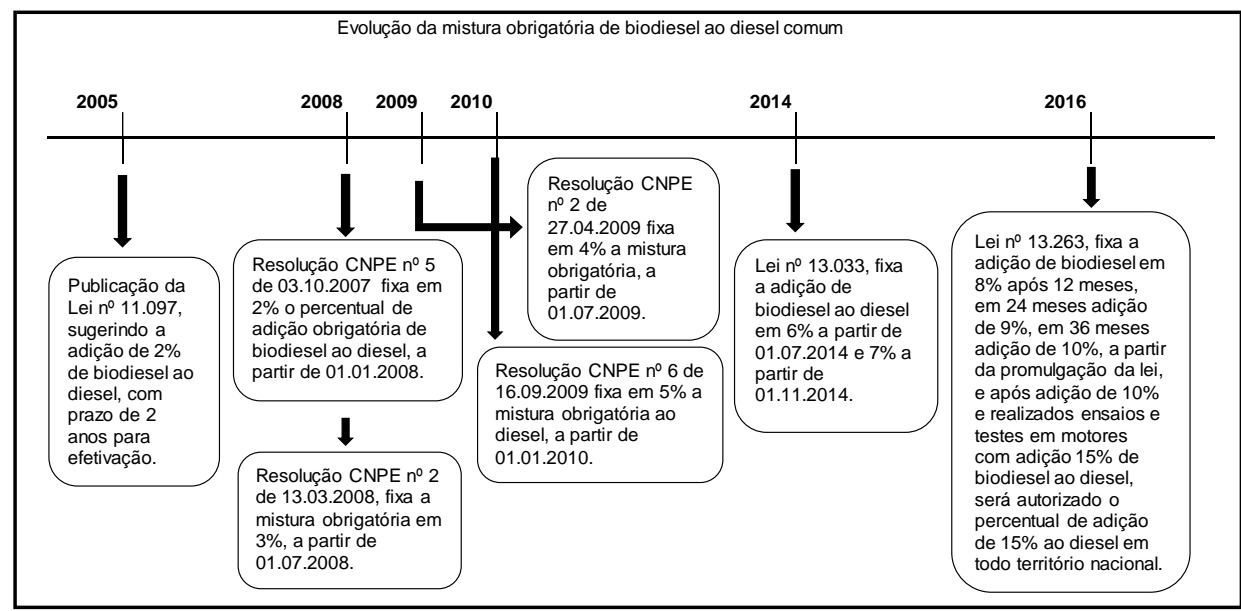

Fonte: Elaboração própria a partir de pesquisa bibliográfica e documental.

Através da Secretária da Agricultura Familiar foi elaborado o Selo Combustível Social (SCS), que é concedido aos produtores de biodiesel que cumprem os critérios previstos no PNPB. Conforme normativas, o SCS obriga os produtores de biodiesel a adquirirem um percentual mínimo de matéria-prima para produção de biodiesel de agricultores familiares. Esse e os demais critérios previstos pelo Selo Combustível

Social são citados a seguir (MDA, 2010; BRASIL, 2015):

- Firmar contratos com agricultores familiares com aval da instituição de classe, como sindicatos e federações, que terá a incumbência de validar o que foi acordado entre as partes;

- Repassar cópia dos contratos assinados pelas partes para o agricultor familiar contratado e para a entidade representativa (sindicato, federação, outros); contratados;

- Assegurar assistência técnica gratuita aos agricultores familiares

- Capacitar os agricultores familiares para produção de oleaginosas, de forma que permita a segurança alimentar da família e com os processos de geração de renda na propriedade, promovendo a inserção de forma ótima da agricultura familiar na cadeia produtiva;

- Repassar cópia do laudo de visita de assistência técnica gratuita ao agricultor familiar, com assinatura do técnico responsável;

- Adquirir percentuais mínimos de matéria-prima proveniente da agricultura familiar, sendo, $15 \%$ nas regiões norte e centro-oeste, $30 \%$ nas regiões sudeste, nordeste e semiárido e 40\% na região sul do país (MDA, 2010; BRASIL, 2015).

Sendo assim, o Programa Nacional de Produção e Uso do Biodiesel (2010), através do Selo Combustível Social, proporciona vantagens ao produtor familiar inserido nesta cadeia produtiva. O agricultor familiar recebe uma bonificação financeira quando vende a sua produção agrícola para produção de biodiesel. Além do mais, as indústrias possuidoras do selo detêm vantagens competitivas frente a outras indústrias que não possuem o selo. É possível citar que as usinas processadoras detentoras do SCS são beneficiadas com a diferenciação/isenção nos tributos PIS/PASEP e COFINS sobre a receita bruta auferida pelo produtor de 
biodiesel, na venda no mercado interno, além de possuírem preferência de venda nos leilões de biodiesel (BRASIL, 2015).

Esclarece-se que a comercialização do biodiesel na cadeia produtiva é regulamentada e executada pela Agência Nacional do Petróleo, Gás Natural e Biocombustíveis, acontecendo através de leilões com a ferramenta de pregões eletrônicos. As produtoras de biodiesel que possuem o SCS têm participação assegurada de $80 \%$ da sua produção nos leilões de biodiesel, que possuem frequência bimestral, com aquisição por meio compulsório do produto (ANP, 2008; MDA, 2010; BRASIL, 2015).

A partir da constituição do marco regulatório do biodiesel no Brasil, a cadeia produtiva foi estruturada. Atualmente, o setor industrial está distribuído em todo território. Na próxima seção, abordam-se as especificidades desta cadeia produtiva no país e no estado do Rio Grande do Sul.

\section{ESTRUTURAÇÃO DA CADEIA PRODUTIVA DO BIODIESEL NO BRASIL E NO RIO GRANDE DO SUL}

Seguindo as orientações do PNPB, formou-se no Brasil uma rede de relações produtivas e comerciais para inserção do biodiesel na matriz energética. No ano de 2008, o setor contava com 62 plantas industriais autorizadas para construção, distribuídas entre os estados brasileiros, dentre as quais somente 2 plantas estavam aptas a comercialização de biodiesel. À época, a capacidade estática autorizada era de 11.023,36 m²/dia (ANP, 2008).

Atualmente, o Brasil conta com 48 usinas processadoras de biodiesel com autorização para comercialização (ANP, 2017). A capacidade instalada de produção e autorizada para comercialização, no final de 2016, foi de $7.306 \mathrm{mil} \mathrm{m} 3 /$ ano. Do total da produção corrente, 92\% possui Selo Combustível Social (MME, 2017). Entre as principais matérias-primas utilizada na produção de biodiesel, no acumulado até novembro de 2016 , destacam-se o grão de soja, com 77,1\% de participação, a gordura bovina, com 15,5\% de participação, e o algodão, com 1,0\% de participação (ANP, 2017).

A Associação Brasileira de Indústrias de Óleos Vegetais (ABIOVE) estima que para a produção de 3 bilhões de litros de biodiesel produzidos a base de óleo de soja no Brasil em 2015, foram utilizados 2,8 milhões de toneladas de óleo de soja. Sendo assim, foram empregados na produção de biodiesel $34 \%$ da produção nacional de óleo de soja do país (ABIOVE, 2016).

Além do mais, a ABIOVE informa que aproximadamente 14 milhões de toneladas de soja foram processadas na produção de biodiesel em 2015 (ABIOVE, 2016). Ainda, a Companhia Nacional de Abastecimento (CONAB) observou que a safra brasileira de soja em 2015 foi de 96,2 milhões de toneladas. Logo, infere-se que, para o ano de $201514,58 \%$ da safra brasileira de soja teve como destino a produção de biodiesel (CONAB, 2016).

A Tabela 1 ilustra a evolução do setor de biodiesel no Brasil até 2016 . Vale destacar que o biodiesel produzido a partir do óleo de soja é predominante, mas outras matérias-primas vêm adquirindo espaço, como é o caso da implementação do sebo bovino para a produção do biocombustível. 
Tabela 1 - Estruturação do setor de biodiesel no Brasil.

\begin{tabular}{|c|c|c|c|c|}
\hline Mês/Ano & $\begin{array}{r}\text { № de plantas } \\
\text { autorizadas a } \\
\text { operação }\end{array}$ & $\begin{array}{r}\text { Capacidade } \\
\text { estática total } \\
\text { autorizada } \\
\mathrm{m}^{3} / \text { dia }\end{array}$ & $\begin{array}{r}\text { Biodiesel } \\
\text { com origem } \\
\text { no óleo de } \\
\text { soja }\end{array}$ & $\begin{array}{r}\% \text { da } \\
\text { capacidade } \\
\text { estática com } \\
\text { Selo } \\
\text { Combustível } \\
\text { Social }\end{array}$ \\
\hline $\begin{array}{l}\text { Dezembro } \\
2008\end{array}$ & 62 & $11.081,03$ & $82,17 \%$ & $91 \%$ \\
\hline $\begin{array}{l}\text { Dezembro } \\
2009\end{array}$ & 63 & $12.933,30$ & $74,04 \%$ & $93 \%$ \\
\hline $\begin{array}{l}\text { Dezembro } \\
2010\end{array}$ & 66 & $16.216,47$ & $80,62 \%$ & $87 \%$ \\
\hline $\begin{array}{l}\text { Dezembro } \\
2011\end{array}$ & 65 & $18.727,95$ & $72,98 \%$ & $75 \%$ * \\
\hline $\begin{array}{l}\text { Dezembro } \\
2012\end{array}$ & 65 & $20.567,76$ & $70,63 \%$ & $88 \%$ \\
\hline $\begin{array}{l}\text { Dezembro } \\
2013\end{array}$ & 64 & $21.957,79$ & $69,24 \%$ & $87 \%$ \\
\hline $\begin{array}{l}\text { Dezembro } \\
2014\end{array}$ & 58 & $21.163,51$ & $74,28 \%$ & $91 \%$ ** \\
\hline $\begin{array}{l}\text { Dezembro } \\
2015\end{array}$ & 53 & $20.366,11$ & $68,97 \%$ & $91 \%$ \\
\hline $\begin{array}{l}\text { Dezembro } \\
2016\end{array}$ & 48 & $20.300,00$ & $77,10 \%$ & $92 \%$ \\
\hline
\end{tabular}

Fonte: Adaptado dos Boletins Mensais dos Biocombustíveis (MME, 2017) e dos Boletins Mensais do Biodiesel expedido pela ANP (2017).

*dado de novembro de 2011.

**dado de setembro de 2014.

É possível notar oscilações na construção do setor produtivo do biodiesel no país. Para o período analisado, ao passo que o número de usinas processadoras foi reduzido, a capacidade estática autorizada para produção praticamente dobrou. Esse efeito pode ser justificado por pequenas usinas que encerraram sua operação e usinas com capacidade maior que obtiveram sua autorização para operação. O percentual de produto expedido com aferição do Selo Combustível Social teve uma leve queda no decorrer dos anos, mas voltou ao número inicial, sendo que $92 \%$ do biodiesel produzido no Brasil provém de matéria-prima da agricultura familiar (ANP, 2015; MME, 2016).

As regiões Sul e Centro-Oeste são detentoras de maior concentração de usinas de biodiesel e de produção de matéria-prima (soja). Para explicar essa liderança, é importante revisitar o processo de consolidação das organizações e instituições para o desenvolvimento do agronegócio brasileiro. Sobretudo, a intensificação do uso da terra, o emprego de tecnologia e a disponibilidade de fatores de produção justificam a preponderância destas regiões no cultivo da soja.

Em especial, vale ressaltar que a cultura da soja foi introduzida no Rio Grande do Sul por volta da década de 1970. Silveira, Gonzáles e Fonseca (2017) destacam que o aumento da área de cultivo de soja no uso da terra nas últimas décadas é condicionado pelo comportamento do mercado externo, ávido demandante de alimentos e produtos primários do Brasil. Assim sendo, os incentivos promovidos pelo aquecimento da demanda internacional e os avanços produtivos - tais como os 
aprimoramentos das técnicas de cultivo e o melhoramento genético - possibilitaram com que a cultura fosse difundida em outras regiões do país (APROSOJA, 2018).

Outro fenômeno importante no cenário nacional e que contribuiu para que o país ocupe posição de destaque no tocante à produção e comercialização de soja foi a ocupação e expansão da fronteira agrícola na região Centro-Oeste. A revolução na agropecuária brasileira, além de qualificar os sistemas já existentes, também tratou de desenvolver novas áreas agriculturáveis. Cunha (2002) afirma que, a partir dos anos 1970, a modernização incentivada pelo poder estatal iniciou seu processo de consolidação. O estado incentivou a instalação de grandes empresas do agronegócio, assim como a instalação de novos produtores e qualificação dos já instalados na região centra do país.

Diante deste contexto, a região Sul detém $75,26 \%$ da sua produção de biodiesel a base de soja. Já a região Centro-Oeste produz $76,24 \%$ do seu biodiesel a base de soja. Em maio de 2017, esta mesma região foi responsável por 70,87\% da produção do biodiesel a base de soja do Brasil (ANP, 2017). Dos estados que compõe a região Centro-Oeste, Goiás, Mato Grosso do Sul e Mato Grosso detêm 21 usinas, as quais representam um volume de produção de 2.867,00 mil mªno. Já a região Sul, composta pelos estados do Paraná, Santa Catarina e Rio Grande do Sul, possui 13 usinas instaladas na região, com volume de produção de $2.918,00 \mathrm{mil} \mathrm{m}^{3} / \mathrm{ano}$ (ANP, 2017).

Assim sendo, para analisar a cadeia produtiva do biodiesel no estado do Rio Grande do Sul, vale-se da noção analítica que abarca a sequência de operações que conduzem à produção e comercialização de produtos finais, bem como as relações de interdependência e complementariedade entre os agentes (MORVAN, 1991). Estes elos podem ser identificados como compreendendo: as indústrias de insumos para lavoura, os produtores agrícolas responsáveis pelo cultivo e originação de grãos nas lavouras, a indústria esmagadora de grãos, as indústrias processadoras de biodiesel e distribuidoras de combustível.

Em síntese, a cadeia produtiva do biodiesel no Rio Grande do Sul engloba desde os fornecedores de insumos, fornecedores de grãos, processamento da matéria-prima até consumidor final. A Figura 3 apresenta o caminho percorrido pelo grão de soja (matéria-prima mais popular no estado gaúcho) em todos os elos da cadeia produtiva do biodiesel. 
Figura 3 - Dinâmica de processamento da soja na cadeia do biodiesel e destino do produto até o consumidor final.

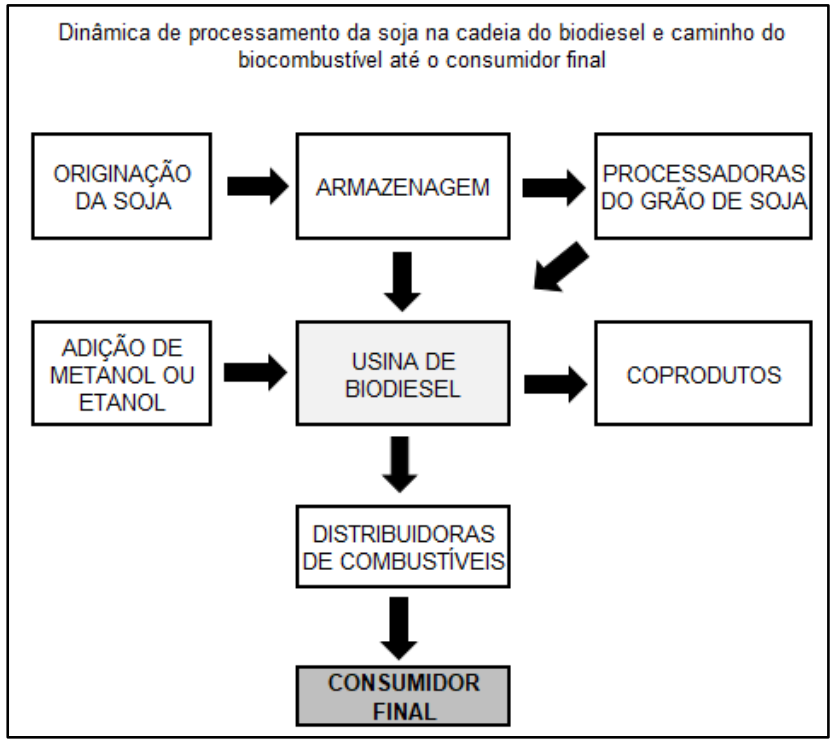

Fonte: Elaboração própria com base em pesquisa bibliográfica.

Conforme representação disposta na Figura 3, a cadeia produtiva do biodiesel tem origem nas atividades agrícolas, responsáveis pela produção do grão soja. Após a colheita, o grão segue para armazenagem em empresas privadas, cooperativas ou cerealistas. Neste elo de armazenagem, o grão recebe tratamento necessário e fica disponível para aquisição por parte das indústrias processadoras de óleo de soja e indústria processadora de biodiesel. A processadora de biodiesel pode adquirir os grãos in natura ou o óleo de soja, dependendo da estrutura industrial que a usina de biodiesel dispõe (WILDNER, 2016).

Com o biodiesel pronto e na qualidade correta exigida pela ANP, o produto está disponível para expedição. O produto é retirado nas usinas de biodiesel pelas distribuidoras de combustíveis que adquiriram o biodiesel no leilão vigente. Em seguida, o biodiesel é adicionado ao diesel e disponibilizado nos postos de combustíveis em todo território nacional.

Zybersztajn (2000) menciona a importância da análise do ambiente institucional e organizacional das cadeias produtivas. Na cadeia do biodiesel do RS, as instituições que regulam e organizam as ações dos agentes econômicos são diversas. Citam-se:

- No âmbito do Ambiente Organizacional: são identificados o papel das universidades públicas e privadas, como a Universidade Federal do Rio Grande do Sul, Universidade Federal de Santa Maria, Universidade de Passo Fundo e Universidade Federal de Pelotas, que desenvolvem pesquisas para 0 desenvolvimento agrícola e desenvolvimento de novas tecnologias de produção do biodiesel. Ainda, no financiamento bancário da lavoura de grãos, destaca-se a atuação dos bancos públicos e privados. Já no financiamento das plantas industriais, cita-se o papel do Banco Nacional do Desenvolvimento (BNDES), que atua no 
fomento do desenvolvimento e aprimoramento do setor. Ademais, menciona-se a importância dos sindicados rurais, das prefeituras municipais, da Emater, dentre outras organizações que dão subsídio para que as atividades produtivas e comerciais sejam consolidadas.

- No âmbito do Ambiente Institucional: mencionam-se as legislações, normas e diretrizes expedidas pela Agência Nacional do Petróleo, Gás Natural e Biocombustíveis, responsável pela regulação e fiscalização da produção e distribuição de biodiesel. Adicionalmente, cita-se o papel desempenhado pelo: Ministério de Minas e Energia, que tem a responsabilidade de orientar e executar a política energética brasileira; Conselho Nacional de Política Energética, responsável por assessorar a presidência da República quanto aos assuntos energéticos; Ministério do Desenvolvimento Agrário, identificado na Secretária da Agricultura Familiar, que tem por responsabilidade realizar a fiscalização da origem dos grãos para concessão do Selo Combustível Social as processadoras de biodiesel, entre outras instituições que fomentam e regulam este mercado energético.

A Figura 4 ilustra a formação dos elos da cadeia no Rio Grande do Sul e as instituições que compreendem os ambientes organizacionais e reguladores da cadeia produtiva.

Figura 4 - Representação dos elos da cadeia produtiva do biodiesel.

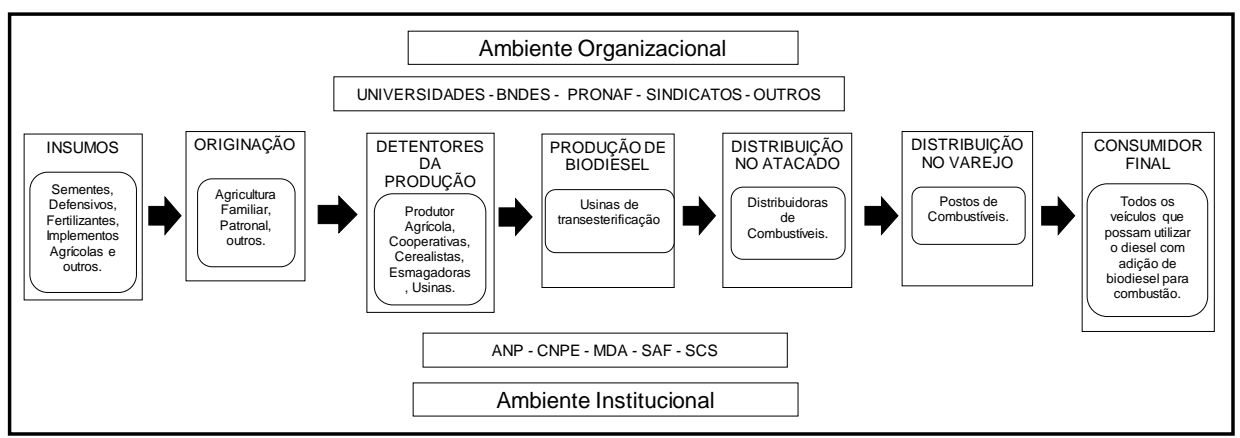

Fonte: Elaboração da autora a partir de Oliveira (2014).

O foco de análise do presente estudo se dá no elo fornecedor de grãos, conforme citado anteriormente. A organização dos agricultores familiares inseridos nesta cadeia produtiva é orienta pelo PNPB para a compra direta ou através de cooperativas agrícolas. Enquanto organizações implementadoras de estratégias de comercialização, as cooperativas proporcionam aos cooperativados benefícios nas transações, assim como adquirem maior competitividade diante do mercado. Portanto, as cooperativas têm papel intermediador no elo fornecedor de grão da cadeia produtiva do biodiesel (MDA, 2010).

No último levantamento realizado pelo Ministério do Desenvolvimento Agrário, estão habilitadas a fornecer matéria-prima para indústrias de biodiesel 112 cooperativas agrícolas em todo Brasil (MDA, 2016). Destas, 12 estão localizadas em Goiás, 14 no Paraná, 18 estão sediadas no estado da Bahia e 41 estão no Rio Grande do Sul.

Em particular, a região Centro-Oeste conta com 16 cooperativas agrícolas. Por sua vez, a região Sul apresenta 64 cooperativas agrícolas. Além do mais, considerando a principal matéria-prima utilizada na produção de biodiesel, as regiões 
Sul e Centro-Oeste detinham aproximadamente $82,54 \%$ (em 2014) e 80,92\% (em 2015) da produção de soja do Brasil (IBGE, 2016).

Diante das informações até então analisadas, constata-se que as cooperativas agrícolas inseridas na cadeia produtiva do biodiesel no Rio Grande do Sul possuem significativa importância perante o PNPB, já que somente o estado gaúcho possui aproximadamente $37 \%$ das cooperativas vinculadas ao SCS. No que tange a representatividade em relação à produção de soja, as cooperativas foram responsáveis por $15 \%$ do total ofertado no país em 2014 e 16,10\% do total ofertado em 2015. Sendo assim, avalia-se a seguir qual o perfil de atuação destas organizações na cadeia produtiva do biodiesel a base do óleo de soja no Rio Grande do Sul.

\section{COOPERATIVAS AGRÍCOLAS FRENTE À CADEIA PRODUTIVA DO BIODIESEL NO RIO GRANDE DO SUL}

Lago (2009) destaca que no cenário atual e no contexto do agronegócio, as cooperativas são estruturas econômicas intermediárias, sua atuação consiste na agregação de valor aos produtos dos associados, que isoladamente teriam condições de competição restritas. Desta maneira, o desempenho das cooperativas visa como resultado uma maior produtividade e rentabilidade para o associado, promovendo a elevação da qualidade de vida, corroborando com os princípios que regem a filosofia cooperativista. Outro papel das cooperativas, é que estas atuam como um importante instrumento regulador de mercado, sendo que sua presença na região promove o desenvolvimento e a sustentabilidade dos associados da cooperativa (LAGO, 2009).

No início do PNPB, o Serviço Nacional de Aprendizagem do Cooperativismo (SESCOOP), instituição ligada à Organização das Cooperativas Brasileiras, iniciou uma série de atividades para verificar as possibilidades de as cooperativas serem inseridas na cadeia produtiva do biodiesel. Dentre as iniciativas realizadas pelo SESCOOP, foi realizada uma pesquisa no mercado de biodiesel brasileiro e a disseminação de informações sobre como realizar a sua inserção na cadeia produtiva em seminários anuais. Conforme o documento da Série Desenvolvimento em Cooperativa "A Inserção das Cooperativas no Processo de Produção do Biodiesel (2008) ":

[...] as cooperativas são peças fundamentais no processo de expansão da produção de oleaginosas para a geração de biocombustíveis no Brasil. [...] sinaliza que o desafio é dar início a um novo ciclo de desenvolvimento rural, socialmente includente e sustentável ambientalmente, e não somente de substituição dos combustíveis (SESCOOP, 2008, p. 49).

O Ministério do Desenvolvimento Agrário, presente nestes seminários, declarou sua posição de apoio às cooperativas. Ainda, demonstrou o interesse em formular uma política conjuntural no fortalecimento da participação das cooperativas na cadeia produtiva do biodiesel, tendo em conta que as cooperativas são de extrema importância nesse processo para inserção dos agricultores familiares na cadeia (SESCOOP, 2008).

O agronegócio gaúcho possui atualmente, conforme levantamento da OCERGS (2016), 132 cooperativas agrícolas ou agropecuárias, sendo que destas, 41 cooperativas estão habilitadas a fornecer matéria-prima a cadeia produtiva do biodiesel no estado. Estas cooperativas estão distribuídas em todo estado. As cooperativas agrícolas presentes no Rio Grande Sul exercem outro papel fundamental 
na cadeia de produção da soja e do biodiesel, a saber, são um dos agentes responsáveis pelo recebimento da produção de grãos dos agricultores. Ainda, são fundamentais para a comercialização destes grãos, em especial, por intermediarem as transações com as usinas de biodiesel, que possuem uma demanda no ano todo e não somente em períodos determinados.

Destaca-se, que da safra de soja do Rio Grande do Sul dos últimos dez anos, as cooperativas vêm recebendo aproximadamente $1 / 3$ do total produzido no estado. Dados estatísticos para a safra 2005/2006, conforme levantamento da FecoAgro e IBGE, apontam que o montante de $35 \%$ da produção do estado é recebido nas cooperativas. Já para a safra $2010 / 2012$, as cooperativas receberam $32 \%$ da soja. $\mathrm{Na}$ última apuração, para safra de 2014/2015, 31\% da produção de soja do estado esteve nos armazéns das cooperativas gaúchas.

A Figura 5 ilustra a evolução do recebimento das cooperativas da cultura da soja, comparada à safra total dos anos selecionados.

Figura 5 - Recebimento da produção da cultura da soja por cooperativas gaúchas, comparado ao total da safra da cultura da soja no RS.

\section{Recebimento da produção de Soja do RS por Cooperativas}

25.000 .000

20.000 .000

$\frac{n}{\frac{\pi}{0}} 15.000 .000$

要 10.000 .000

5.000 .000

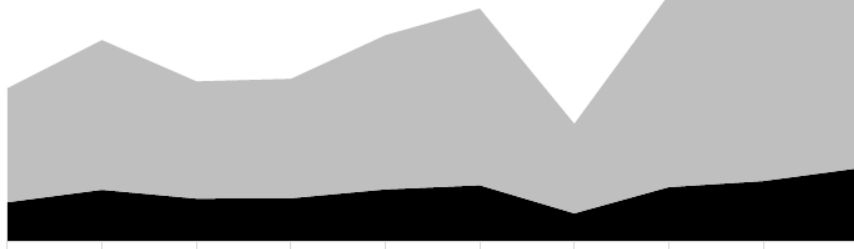

Safras

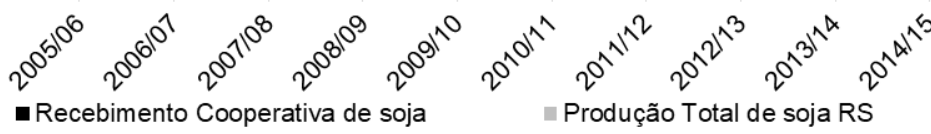

Fonte: Adaptado de FECOAGRO e IBGE (2016).

Tendo em vista as estratégias de atuação das cooperativas frente aos mercados locais, Batalha e Silva (2001) observam que este tipo de organização se configura como importante agente em prol do desenvolvimento das regiões que atuam. As cooperativas se posicionam de forma a obter a melhor performance, o que assegura o desenvolvimento sustentável da organização e trazendo benefícios também aos seus associados. Em vista disso, há promoção de empregos, geração de renda e a multiplicação de sinergias pelo trabalho coletivo realizado. Sendo assim, a relação que as cooperativas desenvolvem com as comunidades em que atuam é uma do tipo ganha-ganha.

Analisando os dados representados na Tabela 2, percebe-se que por mais que o percentual de recebimento das cooperativas no ciclo de dez anos tenha decrescido, passando de $35 \%$ para $31 \%$ do recebimento da safra do estado em seus armazéns, ainda assim o volume de grãos operacionalizados pelas cooperativas é expressivo. A produção de soja no estado vem obtendo recordes de produção a cada 
ano, e as cooperativas continuam a manter seu percentual de recebimento de soja com uma variação relativamente pequena.

No ano/safra 2005/06 a produção de soja no estado foi de aproximadamente 7,5 milhões de toneladas, com recebimentos nas cooperativas de 2,6 milhões de toneladas de soja, recebendo mais de um terço da safra. Já no ano/safra 2014/15, as cooperativas receberam aproximadamente 4,8 milhões de toneladas da safra estadual de 15,7 milhões de toneladas, continuando a receber aproximadamente um terço da safra de soja do estado.

Tabela 2 - Recebimento da produção da soja por parte das cooperativas e o total da safra da cultura no RS.

\begin{tabular}{lrrr}
\hline Ano/Safra & $\begin{array}{c}\text { Recebimento de soja } \\
\text { nas Cooperativas } \\
\text { (mil/ton.) }\end{array}$ & $\begin{array}{r}\text { Produção total de } \\
\text { soja RS (mil/ton.) }\end{array}$ & $\begin{array}{c}\% \text { COOP x } \\
\text { RS }\end{array}$ \\
\hline $2005 / 06$ & 2.630 .375 & 7.559 .288 & $35 \%$ \\
$2006 / 07$ & 3.456 .327 & 9.929 .005 & $35 \%$ \\
$2007 / 08$ & 2.874 .675 & 7.773 .324 & $37 \%$ \\
$2008 / 09$ & 2.899 .267 & 7.913 .000 & $37 \%$ \\
$2009 / 10$ & 3.482 .516 & 10.218 .800 & $34 \%$ \\
$2010 / 11$ & $3.757 .547,76$ & 11.717 .548 & $32 \%$ \\
$2011 / 12$ & $1.894 .729,24$ & 5.945 .243 & $32 \%$ \\
$2012 / 13$ & 3.634 .065 & 12.756 .577 & $28 \%$ \\
$2013 / 14$ & $4.036 .184,64$ & 13.041 .226 & $31 \%$ \\
$2014 / 15$ & $4.880 .066,00$ & 15.700 .264 & $31 \%$ \\
\hline Fonte: Adaptado de FECOAGRO e IBGE $(2016)$ & &
\end{tabular}

Vale ressaltar que, de acordo com critérios do Selo Combustível Social, para serem habilitadas a fornecer matéria-prima às indústrias de biodiesel enquanto representantes da agricultura familiar, as cooperativas precisam ter em seu corpo de associados no mínimo $60 \%$ dos cooperados considerados agricultores familiares. Esta classificação é realizada através da Declaração de Aptidão ao Pronaf (DAP) pessoa física ativa e jurídica (MDA, 2014). Da mesma forma, para concessão do SCS, as processadoras de biodiesel têm de realizar a aquisição de pelo menos $40 \%$ do volume da matéria-prima para a produção de biodiesel com origem na agricultura familiar. Sendo assim, as cooperativas tornam-se importante fornecedora de matéria-prima para cadeia do biodiesel, sendo representantes dos agricultores familiares e deterem volume de produção e armazenagem de grão suficiente para atender a produção de biodiesel o ano todo. No final deste ciclo, a processadora de biodiesel que adquire soja com DAP das cooperativas no percentual necessário, obtém o SCS e é beneficiada no PIS/COFINS e nos leilões de aquisição de biodiesel (MDA, 2010; BRASIL, 2015).

A Figura 6 apresenta os vínculos pelos quais o PNPB prevê a inclusão dos agricultores familiares à cadeia produtiva do biodiesel. 
Figura 6 - Importância das cooperativas frente a cadeia produtiva do biodiesel no RS.

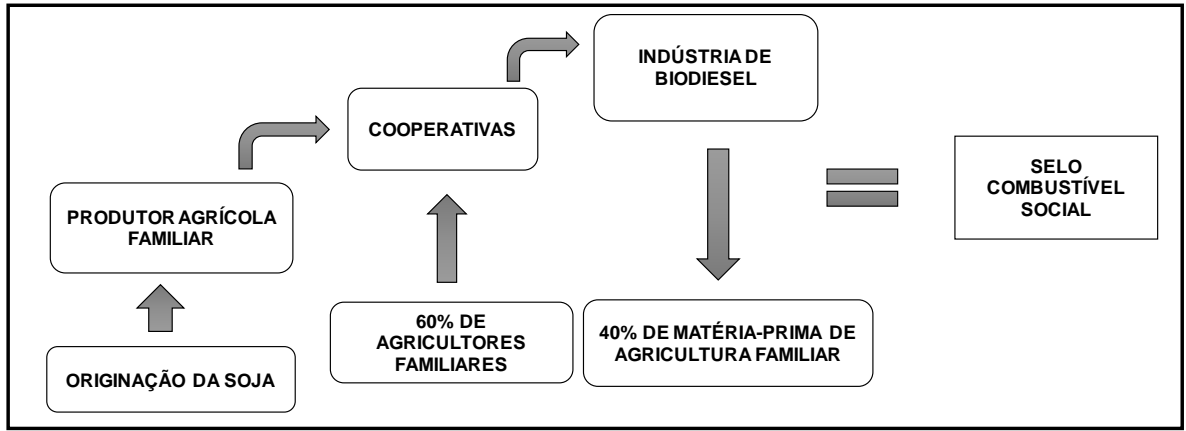

Fonte: Elaboração própria com base em pesquisa documental.

As cooperativas são importantes organizações de intermediação entre os agricultores familiares e processadoras do biocombustível. Abicht et al. (2014) destacam a importância das cooperativas, alegando que estas possuem maior poder de barganha quando se dá a negociação com indústrias de biodiesel, fato condicionado pelo volume representativo de grão que detém para ser ofertado no mercado (por ser representante de vários produtores familiares). Os autores relatam ainda que as cooperativas podem estabelecer parcerias comerciais com outras cooperativas, elevando seu poder de barganha frente às indústrias processadoras do biocombustível.

Nestes termos de competitividade, as cooperativas podem ajustar os instrumentos contratuais de comercialização dos grãos com maior flexibilidade, tanto em relação ao valor das negociações dos volumes, quanto em relação a ocasionais renegociações dos termos de comercialização por alterações no mercado (ABICHT et al., 2014). Sobretudo, argumenta-se que as cooperativas gaúchas desenvolvem múltiplos canais de comunicação com os produtores agrícolas associados. Estes canais proporcionam à cooperativa a oportunidade de ser beneficiada pelo Selo Combustível Social. Na esfera de inclusão de pequenos agricultores ao mercado energético, a assistência técnica ofertada pelas cooperativas aos produtores rurais permite a estes expandirem sua renda e atividade produtiva através da potencialização dos seus processos com novas tecnologias produtivas e de negócios, consolidando com um forte canal de ligação entre as partes. Estas ações fortalecem as potencialidades regionais e promovem o desenvolvimento local.

Considerando a significativa importância das cooperativas gaúchas ao agronegócio do estado, aliado aos compromissos estipulados no PNPB em relação ao desenvolvimento e fortalecimento das potencialidades regionais, torna-se importante compreender os cenários interno e externo das cooperativas inseridas na cadeia produtiva do biodiesel a base de soja no Rio Grande do Sul.

\section{CONSIDERAÇÕES FINAIS}

As cooperativas agrícolas gaúchas são importantes players nos mercados agropecuários e contribuintes para o desenvolvimento das comunidades em que atuam. A força e capacidade de atuação nos diferentes espaços de trocas se dá através da união dos produtores rurais que a constituem. Esse compromisso realizado 
entre instituição e cooperados dá significado a filosofia da ajuda mútua e impulsiona o desenvolvimento da região de atuação da própria organização.

Com a implementação do Programa Nacional de Produção e Uso do Biodiesel e a consequente estruturação da cadeia produtiva do biodiesel, as cooperativas produtoras e comercializantes de commodities ganharam novo espaço no mercado energético nacional. A proposta do selo combustível social, prevista no PNPB, remunera mais os produtores agrícolas familiares, fato que legitima ainda mais a inserção das cooperativas neste setor. Essa legitimação é explicada na possibilidade de progresso financeiro e social que a cooperativa pode proporcionar ao agricultor familiar, como melhores preços nos insumos, assistência técnica, armazenagem da produção, educação financeira e para vida. Portanto, dentre outras funções sociais, as cooperativas apresentam significativas ações de fomento da agricultura familiar e ao desenvolvimento rural.

No Rio Grande do Sul, aproximadamente 31\% das cooperativas atuantes se inserem na cadeia produtiva do biodiesel. Estas atuam como intermediárias e facilitadores da produção, distribuição e comercialização agrícola. Algumas organizações oferecem serviços de assistência técnica e coordenam a logística de transbordo da produção. Nestes termos, justifica-se que as cooperativas agrícolas promovem ações que permitem o desenvolvimento da cadeia produtiva do biodiesel, bem como o desenvolvimento regional.

A expressão do cooperativismo no Rio Grande do Sul é notável, isso devese ao estado ser o berço de diversas ações e organizações cooperativas, a citar as de crédito e do ramo agropecuário. A cultura de ajuda mútua condicionou a dinamização e o crescimento de muitas regiões rurais do estado. Assim, o modelo de cooperação foi uma das estratégias utilizadas para promover o desenvolvimento da agricultura e pecuária no estado gaúcho, buscando atender os objetivos comerciais de forma concomitante ao desenvolvimento das comunidades que as constituíam.

Diante da preocupação das organizações privadas e públicas com 0 desenvolvimento sustentável, espera-se que as cooperativas possam continuar a desenvolver as regiões em que atuam, em particular das comunidades mais vulneráveis social e economicamente. Essas organizações, além de agentes econômicos, são agentes de desenvolvimento social, com alto potencial para promover qualidade de vida e bem-estar aos seus cooperados.

Ressalva-se que os agricultores familiares possuem uma condição, por vezes, delicada frente ao ambiente competitivo dos mercados agrícolas. Por isto, a assistência técnica e extensão rural promovida e incentivada pelas cooperativas podem significar o progresso das atividades produtivas que desempenham. Além do mais, as organizações cooperativas podem figurar como veículos importantes ao acesso de novos mercados. A consolidação do PNPB instrumentalizou a cadeia do biodiesel para acolher a produção de agricultores familiares, de tal forma que o mercado energético pode ser mais uma possibilidade de constituição de renda para os produtores rurais.

\section{REFERÊNCIAS}

ABICHT, A.M.; CEOLIN, A.C.; PEREIRA, P.R.R.X.; CORREA, A.O. de F. As relações entre o produtor rural a cooperativa e a indústria na produção de biodiesel sob a ótica da ECT. REDES - Revista de Desenvolvimento Regional, Santa Cruz do Sul, v.19, n.1, p.93-109, jan./abr. 2014. Disponível em: http://online.unisc.br/seer/index.php/redes/article/view/2197. Acesso em: 14 out. 2015. 
ABIOVE. Associação das Indústrias de Óleos Vegetais, 2016 [mensagem pessoal]. Mensagem recebida de <fguerra@abiove.org.br>. Acesso em: 13 jun. 2016.

ANP. Boletim Mensal do Biodiesel - Dezembro de 2009. Rio de Janeiro: ANP, 2009.

ANP. Boletim Mensal do Biodiesel - Dezembro de 2010. Rio de Janeiro: ANP, 2010.

ANP. Boletim Mensal do Biodiesel - Dezembro de 2011. Rio de Janeiro: ANP, 2011.

ANP. Boletim Mensal do Biodiesel - Dezembro de 2012. Rio de Janeiro: ANP, 2012.

ANP. Boletim Mensal do Biodiesel - Dezembro de 2013. Rio de Janeiro: ANP, 2013.

ANP. Boletim Mensal do Biodiesel - Dezembro de 2014. Rio de Janeiro: ANP, 2014.

ANP. Boletim Mensal do Biodiesel - Dezembro de 2015. Rio de Janeiro: ANP, 2015.

ANP. Boletim Mensal do Biodiesel - Dezembro de 2016. Rio de Janeiro: ANP, 2016.

ANP. Boletim Mensal do Biodiesel - Fevereiro de 2017. Rio de Janeiro: ANP, 2017.

ANP. Boletim Mensal do Biodiesel - Novembro de 2008. Rio de Janeiro: ANP, 2008.

APROSOJA. A história da soja. Cuiabá: Aprosoja, 2018. Disponível em: <http://www.aprosoja.com.br/soja-e-milho/a-historia-da-soja>. Acesso em: 28 dez. 2018.

BATALHA, M.O.; DA SILVA, A.L. Gerenciamento de Sistemas Agroindustriais: Definições e Correntes Metodológicas. In: BATALHA, M.O. (Coord.). Gestão agroindustrial. 2.ed. São Paulo: Atlas, 2001.

BRASIL. Conselho Nacional de Política Energética. Resolução no $\mathbf{0 5}$, de 03 de outubro de 2007. Estabelece diretrizes gerais para a realização de leilões públicos para aquisição de biodiesel, em razão da obrigatoriedade legal prevista na Lei no 11.097, de 13 de janeiro de 2005, e dá outras providências. Brasília: CNPE, 2007.

BRASIL. Conselho Nacional de Política Energética. Resolução no 02, de 13 de março de 2008. Estabelece em três por cento, em volume, o percentual mínimo obrigatório de adição de biodiesel ao óleo diesel comercializado ao consumidor final, nos termos do art. $2^{\circ}$ da Lei no 11.097, de 13 de janeiro de 2005. Brasília: CNPE, 2008.

BRASIL. Conselho Nacional de Política Energética. Resolução no 02, de 27 de abril de 2009. Estabelece em quatro por cento, em volume, o percentual mínimo obrigatório 
de adição de biodiesel ao óleo diesel comercializado ao consumidor final, de acordo com o disposto no art. $2^{\circ}$ da Lei $\mathrm{n}^{\circ}$ 11.097, de 13 de janeiro de 2005. Brasília: CNPE, 2009.

BRASIL. Conselho Nacional de Política Energética. Resolução nº 06, de 16 de setembro de 2009. Estabelece em cinco por cento, em volume, o percentual mínimo obrigatório de adição de biodiesel ao óleo diesel comercializado ao consumidor final, de acordo com o disposto no art. $2^{\circ}$ da Lei $n^{\circ} 11.097$, de 13 de janeiro de 2005. Brasília: CNPE, 2009.

BRASIL. Ministério do Desenvolvimento Agrário. Portaria nํ 337, de 18 de setembro de 2015. Dispõe sobre os critérios e procedimentos relativos à concessão, manutenção e uso do Selo Combustível Social. Diário Oficial da União, Brasília, DF, 22 set. 2015. Seção 1, p. 65-69.

BRASIL. Presidência da República. Lei no 11.097, de 13 de janeiro de 2005. Dispõe sobre a introdução do biodiesel na matriz energética brasileira; altera as Leis nos 9.478 , de 6 de agosto de 1997, 9.847, de 26 de outubro de 1999 e 10.636, de 30 de dezembro de 2002; e dá outras providências. Diário Oficial da União, Brasília, DF, 14 jan. 2005. Seção 1, p. 8.

BRASIL. Presidência da República. Lei no 13.033, de 24 de setembro de 2014. Dispõe sobre a adição obrigatória de biodiesel ao óleo diesel comercializado com o consumidor final; altera as Leis nos 9.478, de 6 de agosto de 1997, e 8.723, de 28 de outubro de 1993; revoga dispositivos da Lei no 11.097, de 13 de janeiro de 2005; e dá outras providências. Diário Oficial da União, Brasília, DF, 25 set. 2014. Seção 1, p. 3.

BRASIL. Presidência da República. Lei n. 13.263, de 23 de março de 2016. Altera a Lei $n \underline{0}$ 13.033, de 24 de setembro de 2014, para dispor sobre os percentuais de adição de biodiesel ao óleo diesel comercializado no território nacional. Diário Oficial da União, Brasília, DF, 24 mar. 2016. Seção 1, p. 1.

BRASIL. Presidência da República. Lei no 5.764 de 16 de dezembro 1971. Define a Política Nacional de Cooperativismo, institui o regime jurídico das sociedades cooperativas, e dá outras providências. Diário Oficial da União, Brasília, DF, 16 dez. 1971. Seção 1, p. 10354.

CONAB. Companhia de Abastecimento Nacional. 2016. Disponível em: <http://www.conab.gov.br/>. Acesso em: 10 set. 2015.

CUNHA, J.M.P. A migração no Centro-Oeste brasileiro no período 1970-96: o esgotamento de um processo de ocupação. Campinas: Núcleo de Estudos de População/UNICAMP, 2002.

DORNELES, M.A. da R.; SILVEIRA, V.C.P. A ação extensionista da cadeia do biodiesel no município Cachoeira do Sul, Rio Grande do Sul, Brasil. Extensão Rural, Santa Maria, v.21, n.3, set./dez. 2013. Disponível em: https://periodicos.ufsm.br/extensaorural/article/view/7601. Acesso em: 28 dez. 2018.

FAO. Cooperativas agrícolas, a chave para reduzir a fome e a pobreza. 2016. Disponível em: https://www.fao.org.br/cacrfp.asp. Acesso em: 09 mar. 2016. 
FECOAGRO. Federação das Cooperativas Agropecuárias do Rio Grande do Sul, 2015 [mensagem pessoal]. Mensagem recebida de <feltraco@redeagro.com.br>. Acesso em: 14 ago. 2017.

FECOAGRO. Federação das Cooperativas Agropecuárias do Rio Grande do Sul. 2017.

GRAEF, N.D. Análise do sistema agroindustrial (SAI) do biodiesel no Paraná com enfoque na nova economia institucional. 2012. 137f. Dissertação (Mestrado em Desenvolvimento Regional e Agronegócio) - Programa de Pós-Graduação em Desenvolvimento Regional e Agronegócio, Universidade Estadual do Oeste do Paraná.

IBGE. Produção agrícola municipal. Brasília: IBGE, 2016.

KNOTHE, G.; GERPEN, J.V.; KRAHL, J.; RAMOS, L.P. Manual de biodiesel. São Paulo: Blucher, 2006

LAGO, A. Fatores condicionantes do desenvolvimento de relacionamentos intercooperativos no cooperativismo agropecuário. 2009. 179f. Tese (Doutorado em Agronegócios) - Programa de Pós-Graduação em Agronegócios, Universidade Federal do Rio Grande do Sul. Disponível em: http://www.lume.ufrgs.br/bitstream/handle/10183/18439/000729139.pdf?sequence=. Acesso em: 15 ago. 2015.

LLORENS, F.A. Desenvolvimento econômico local: caminhos e desafios para construção de uma nova agenda política. Rio de Janeiro: BNDES, 2001.

MAIA, R.R. da S. Programa Nacional de Produção e Uso de Biodiesel (PNPB): implicações de uma Análise Custo Benefício. 2012. 117f. Dissertação (Mestrado em Gestão Econômica do Meio Ambiente) - Programa de Pós-Graduação do Departamento de Economia - Centro de Estudos em Economia, Meio Ambiente e Agricultura (CEEMA), Universidade de Brasília. Disponível em: http://www.ceemaunb.com/dissertacoes2015/120.pdf. Acesso em: 05 out. 2015.

MDA. Cooperativas habilitadas no PNPB. Brasília: MDA, 2016.

MDA. Portaria no 21 de 27 de março de 2014 [Alterada pela Portaria $n^{\circ} 33$, de 15 de maio de 2014, publicada no DOU $n^{\circ} 91$, de 15 de maio de 2014, página 64, Seção 1 - Republicada] estabelece as condições e procedimentos gerais para a emissão de Declaração de Aptidão ao Pronaf - DAP. Diário Oficial da União, Brasília, DF, 15 mai. 2014. Seção 1, p. 64.

MDA. Programa Nacional de Produção e Uso do Biodiesel. Brasília: MDA, 2010.

MME. Boletim mensal dos combustíveis renováveis. Ministério de Minas e Energia, ed. 107, jan./fev. 2017.

MME. Boletim mensal dos combustíveis renováveis. Ministério de Minas e Energia, ed. 12, dez. 2008. 
MME. Boletim mensal dos combustíveis renováveis. Ministério de Minas e Energia, ed. 24, dez. 2009.

MME. Boletim mensal dos combustíveis renováveis. Ministério de Minas e Energia, ed. 36, dez. 2010.

MME. Boletim mensal dos combustíveis renováveis. Ministério de Minas e Energia, ed. 47, nov. 2011.

MME. Boletim mensal dos combustíveis renováveis. Ministério de Minas e Energia, ed. 59, dez. 2012.

MME. Boletim mensal dos combustíveis renováveis. Ministério de Minas e Energia, ed. 71, dez. 2013.

MME. Boletim mensal dos combustíveis renováveis. Ministério de Minas e Energia, ed. 71, dez. 2013.

MME. Boletim mensal dos combustíveis renováveis. Ministério de Minas e Energia, ed. 81, out. 2014.

MME. Boletim mensal dos combustíveis renováveis. Ministério de Minas e Energia, ed. 91, ago. 2015.

MME. Boletim mensal dos combustíveis renováveis. Ministério de Minas e Energia, ed. 95, dez. 2015.

MME. Boletim mensal dos combustíveis renováveis. Ministério de Minas e Energia, ed. 99, mai. 2016.

MME. Boletim mensal dos combustíveis renováveis. Ministério de Minas e Energia, ed. 99, mai. 2016.

MME. Portaria no 116, de 04 de abril de 2013. Estabelecimento de diretrizes específicas para a formação de estoques de biodiesel no País. Brasília: MME, 2013.

MORVAN, Y. Fondaments d'economie industrielle. Paris: Econômica, 1991.

OCERGS. Organização das Cooperativas do Rio Grande do Sul. 2016. Disponível em: <http://www.ocergs.coop.br/>. Acesso em: 11 out. 2015.

PEDRINI, G.R. Cadeia produtiva do biodiesel produzido a partir do óleo de soja no estado de Mato Grosso do Sul. 2012. 100f. Dissertação (Mestrado em Administração) - Programa de Pós-Graduação em Administração, Universidade Federal de Mato Grosso do Sul. Disponível em: http://200.129.202.51:8080/jspui/handle/123456789/1626. Acesso em: 25 out. 2015.

PNPB. Programa Nacional de Produção de Biodiesel. [2010].

QUESSADA, T.P., GUEDES, L.B., BORSATO, D. Obtenção de biodiesel a partir de óleo de soja e milho utilizando catalisadores básicos e catalisador ácido. Enciclopédia Biosfera, Goiânia, v.6, n.11 p.1-25, 2010. 
SESCOOP. A inserção das cooperativas no processo de produção do biodiesel. Série Desenvolvimento em Cooperativa. Serviço Nacional de Aprendizagem do Cooperativismo. 2008

Disponível

em:

http://www.ocb.coop.br/GERENCIADOR/ba/arquivos/biodiesel_28_11.pdf. Acesso em: 13 out. 2015.

SILVEIRA, V.C.P.; GONZALEZ, J.A.; FONSECA, E.L. Land use changes after the period commodities rising price in the Rio Grande do Sul State, Brazil. Ciência Rural, Santa Maria, v.47, n.4, $2017 . \quad$ Disponível em: http://www.scielo.br/scielo.php?script=sci_arttext\&pid=S0103-

$84782017000400931 \&$ Ing=en\&nrm=iso. Acesso em: 29 dez. 2018.

WILDNER, M.C. Cooperativas agropecuárias frente à cadeia produtiva do biodiesel no Rio Grande do sul: uma análise a partir do modelo linguístico SWOT-FUZZY. 2016. 242f. Dissertação (Mestrado em Economia e Desenvolvimento) - Programa de Pós-Graduação em Economia e Desenvolvimento, Universidade Federal de Santa Maria. Disponível em: http: https://repositorio.ufsm.br/bitstream/handle/1/6631/WILDNER,\%20MARLUCI\%20CA SALINI.pdf?sequence=1. Acesso em: 25 out. 2018.

ZYLBERSZTAJN, D. Conceitos Gerais, Evolução e Apresentação do Sistema Agroindustrial. In: ZYLBERSZTAJN, D.; NEVES, M.F. (Org.) Economia e Gestão de Negócios Agroalimentares. São Paulo: Pioneira, 2000. p.1-22. 